\title{
Grietas en las fronteras: insurgencias migrantes en Canadá, solidaridad, refugio, y protección de la vida en los tiempos del Covid-19
}

\author{
Sección ESTUDI0S \\ RECIBIDO: 15/10/2021 \\ APROBADO: 10/11/2021 \\ PUBLICADO ONLINE: 30/12/2021
}

\author{
Eloy Rivas-Sánchez ${ }^{1}$ \\ Athabasca University \\ hrivassanchez@athabascau.ca \\ https://orcid.org/0000-0002-3482-1478
}

\section{RESUMEN}

En el contexto del covid-19, el Estado canadiense ha respondido a la emergencia sanitaria implementando políticas de apoyo para las y los ciudadanos canadienses y aquellas poblaciones que están permitidos de habitar en el territorio canadiense de forma legal. Estas políticas, que excluyen a las poblaciones de migrantes que habitan en el territorio de forma "ilegal", han tenido como efecto el fortalecimiento y proliferación de las fronteras, externas e internas, que excluyen a las y los migrantes sin estatus y otros migrantes de estatus precario. Frente a esto, las poblaciones de indocumentados y las organizaciones políticas aliadas a estas poblaciones se han movilizado políticamente para brindar protección y refugio de emergencia hacia quienes han sido excluidos en el contexto de la pandemia, así como para demandar estatus legal universal para las y los "sin papeles". Como resultado de estas luchas, las poblaciones de inmigrantes precarios parecen estar disputando y sometiendo a contradicciones los regímenes dominantes de significación, vigilancia, y delimitación de las fronteras. Sus insurgencias colectivas, es el argumento que se desarrolla en este artículo, parecen estar también reinventando una nueva forma de hacer política que coloca en el centro la protección y prolongación cualitativa de la vida, así como reescribiendo nuevas narrativas sobre el espacio, sobre su pertenencia al territorio canadiense, y sobre el significado que la frontera tiene para ellos.

Estas reflexiones se basan en un trabajo etnográfico sobre las movilizaciones de las y los migrantes indocumentados en Montreal, Canadá en el contexto de la emergencia sanitaria generada por el covid-19. El trabajo investigativo ha consistido en el registro de imágenes y narrativas de activistas a través de entrevistas a profundidad, registro de imágenes, y el involucramiento continuo en las luchas sociales de las y los indocumentados en sobre las cuales se reflexiona en este artículo.

PALABRAS CLAVE: Migracion indocumentada; fronteras; movimientos sociales; solidaridad social; Covid19

1 Profesor-investigador, Centro para las Ciencias Sociales, Athabasca University (Alberta, Canadá). Profesor de Investigación Adjunto, Departamento de Sociología y Antropología, Carleton University (Ottawa, Canadá). Office: 1 (403) 312-4292. Toll free (Canada and U.S.): 1-844-549-2090

(c) Los autores. Este artículo es publicado por la Revista de Sociología de la Facultad de Ciencias Sociales, Universidad Nacional Mayor de San Marcos. Este es un artículo de acceso abierto, distribuido bajo los términos de la licencia Creative Commons Atribución 4.0 Internacional (CC BY 4.0) [https://creativecommons.org/licenses/by/4.0/deed.es] que permite el uso, distribución y reproducción en cualquier medio, siempre que la obra original sea debidamente citada de su fuente original. 


\title{
Cracks in the Borders: Migrant Insurgencies in Canada, solidarity, refuge, and protection of life in the times of covid-19
}

\begin{abstract}
In the context of covid-19, the Canadian State has responded to the health emergency by implementing support policies for Canadian citizens and those populations that are allowed to live in Canadian territory legally. These policies, which exclude migrant populations that inhabit the territory "illegally", have had the effect of strengthening and proliferating borders, external and internal, which exclude migrants without status and other migrants from precarious status. Faced with this, the undocumented populations and the political organizations allied to these populations have mobilized politically to provide protection and emergency shelter to those who have been excluded in the context of the pandemic, as well as to demand universal legal status for them. "undocumented". As a result of these struggles, precarious immigrant populations appear to be contesting and subjecting to contradictions the dominant regimes of significance, surveillance, and boundary delineation. Their collective insurgencies, is the argument that is developed in this article, they also seem to be reinventing a new way of doing politics that places the protection and qualitative prolongation of life at the center, as well as rewriting new narratives about space, about their belonging to Canadian territory, and about the meaning that the border has for them.

These reflections are based on an ethnographic work on the mobilizations of undocumented migrants in Montreal, Canada in the context of the health emergency generated by covid-19. The investigative work has consisted in the recording of images and narratives of activists through in-depth interviews, recording of images, and the continuous involvement in the social struggles of the undocumented on which this article is reflected.
\end{abstract}

KEYWORDS: Undocumented migration; Borders; Social Movements; Social Solidarity; Covid19

\section{Introducción}

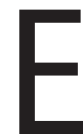

n el contexto de la emergencia sanitaria generada por el covid-19, el Estado canadiense ha implementado una serie de políticas institucionales orientadas a la protección de la salud, la contención de la expansión del virus, la protección de la seguridad social y la expansión de formas de apoyo institucional para las y los ciudadanos canadienses y aquellas poblaciones que están permitidas de habitar en el territorio canadiense de forma legal. En consonancia con las políticas de salud y seguridad implementadas en otros países del mundo, las políticas del Estado canadiense han incluido: el cierre parcial y temporal de las fronteras territoriales; la suspensión temporal de la recepción de solicitudes de refugio de quienes llegan por tierra desde los Estados Unidos; la rigurosa administración de las poblaciones que ingresan al país por aire y por tierra, y que circula al interior del mismo; la puesta en marcha de toques de queda en algunas provincias; la cuarentena obligatoria en ciertos momentos; el cierre de espacios públicos y privados de trabajo, servicio y esparcimiento; el acceso universal a las pruebas y vacunas relacionadas con el covid-19 
reguladas por estrictos registros de identidad; la implementación de pasaportes covid; el apoyo financiero de emergencia para los desempleados por motivo de las disrupciones asociadas con la crisis sanitaria, entre otros. Aunque estas medidas han resultado relativamente efectivas para la contención de la expansión del virus, así como para brindar protección a la salud y la seguridad social de las y los ciudadanos canadienses en estos momentos de crisis, han tenido también como efecto lo que en este trabajo denominamos, siguiendo a Sandro Mezzadra y Brett Neilson (2013) “la multiplicación de las fronteras." Esto es, en la medida que las políticas de apoyo a la seguridad ciudadana implementadas por el Estado han excluido a las y los migrantes indocumentados, y en la medida que tales políticas han facilitado el registro escrupuloso de la identidad de quienes acuden a los servicios de salud, la vigilancia puntual de los centros de trabajo, espacios públicos de servicio y esparcimiento, así como también facilitado una vigilancia y control puntual de la movilidad poblaciones que llegan al país o que circula dentro del mismo, tales políticas han vulnerado de manera profunda la seguridad de quienes habitan en el territorio de forma irregular, los llamados "inmigrantes ilegales", los han excluido del espacio social, y han incrementado su experiencia de asilamiento y "deportabilidad."

Este trabajo se dividide en tres partes. En la primera parte se presenta una breve reflexión teórica sobre las fronteras y el poder. En particular, en esta primera parte se discute sobre la forma en que las fronteras, tanto como mecanismos externos de demarcación territorial y como elementos subjetivos de control social, se han transformado y expandido en el capitalismo avanzado. En una segunda parte, y haciendo referencia al contexto canadiense, se reflexiona sobre a) la forma en que las fronteras se han multiplicado en el marco de la emergencia del covid-19, y b) sobre la manera en que esta proliferación de las fronteras y sus exclusiones están siendo disputadas por los movimientos y prácticas sociales de solidaridad. Finalmente, en un tercer apartado, el artículo reflexiona sobre las posibles implicaciones de tales luchas para las políticas emancipatorias actuales en el contexto canadiense.

Este trabajo pretende mostrar que las luchas e insurgencias sociales llevadas a cabo por las poblaciones de inmigrantes indocumentados y sus organizaciones aliadas en el marco de la emergencia sanitaria del covid-19 parecen estar disputando y sometiendo a contradicciones los regímenes dominantes de significación, vigilancia, y delimitación de las fronteras. Sus insurgencias colectivas, es el argumento que se desarrolla, parecen estar también reinventando una nueva forma de política que coloca en el centro la protección y prolongación cualitativa de la vida, así como reescribiendo nuevas narrativas sobre el espacio, sobre su pertenencia al territorio canadiense, y sobre el significado que la frontera tiene para ellos. 


\section{Definiendo las fronteras}

as fronteras pueden ser definidas como dispositivos de demarcación espacial, y también como el conjunto de representaciones cognitivas, culturales que, como dice Étienne Balibar, (2002) "definen, delimitan y registran las características de un territorio" (p. 76) así como la identidad de las comunidades que en ellas habitan. Definidas de esta forma; esto es, como dispositivos de demarcación territorial, cultural, política y moral, podemos decir que la principal función de las fronteras es la de establecer un adentro y un afuera; un límite entre lo permitido y lo proscrito; entre lo legal y lo ilegal; entre lo deseable y lo repulsivo, así como la diferencia entre aquello que pertenece y aquello que es ajeno a un territorio $o$ espacio social.

Pero las fronteras, sus demarcaciones, no operan sólo de forma heteronómica, o de "arriba hacia abajo" En la medida en que éstas ordenan sobre las comunidades que en ellas habitan una identidad, un sentido de los límites, así como un castigo a sus transgresiones, las fronteras se incorporan en los sujetos sociales en la forma de habitus; esto es, se materializan en los sistemas de disposiciones duraderas que estructuran los esquemas de representación, percepción, sentimiento y acción de los sujetos (Bourdieu, 2012, p. 72). Por tanto, las fronteras se actualizan, significan, reproducen y contestan en las relaciones sociales en el día a día. Por esta razón, como afirma Mezzadra y Nelson (2015), las fronteras deben ser pensadas, sobre todo, como relaciones sociales -de poder y resistencia- cuyos límites, contornos, significados, cambian como resultado de las luchas sociales por (re)afirmarlas, cruzarlas, (re)definirlas, (re)producirlas, o disputarlas.

\section{Economía política de la frontera}

Utilizando los principios de la crítica de la economía política del sistema mundo desarrollado por el sociólogo Immanuel Wallerstein y otros, se puede afirmar que las fronteras, como mecanismos externos de demarcación territorial, juegan un papel central en el mantenimiento del sistema de relaciones interestatales, lo cual es crucial también para el funcionamiento del capitalismo en el sistema mundo (Wallerstein, 2004, pp. 5-47 y 2011).

Las fronteras, tanto como mecanismos externos de demarcación espacial como realidades incorporadas en la subjetividad de los agentes sociales, parecen estar principalmente trazadas, reafirmadas, o impugnadas por tres instituciones 
fundamentales, las cuáles operan a menudo en sentido divergente: El Estado, el capital y la sociedad civil. El Estado es la institución soberana encargada de afirmar, vigilar, y reforzar las reglas sobre las cuáles las mercancías, el capital y el trabajo son permitidas de cruzar las fronteras, así como de operar dentro de las mismas. La administración selectiva de la población, y de su circulación, en el marco de su soberanía es otra característica del papel que juega el Estado en el uso de las fronteras. Este proceso se lleva a cabo por medio de dos mecanismos. Primero, a través de la implementación de marcos regulatorios que norman los límites geográficos, las formas de circulación dentro y a través de tales límites geográficos, y también los derechos y obligaciones, a menudo diferenciadas, a los que deben adscribirse los sujetos que habitan dentro de un territorio soberano. Segundo, a través de la vigilancia y conservación de sus límites fronterizos por medio de lo que Foucault (2009, pp. 29-54) ha denominado los aparatos de seguridad biopolítica. Estos mecanismos estatales de vigilancia y control de la frontera, así como de los límites geográficos, legales, morales, son también incorporados por los individuos a través de procesos de interpelación o subjetivación, que inscriben en los sujetos sociales la territorialización, el límite, la transgresión y el miedo (Deleuze y Guattari, 2009).

El capital, por otro lado, es una fuerza que a menudo opera en sentido contrario. En su continua tendencia hacia la acumulación, como ha teorizado Marx (1977, pp. 516-525) el capital tiende hacia la inflexión, aniquilación o derrumbe de todo límite fronterizo, geográfico, legal o cultural, que impide su expansión. Pero también tiende hacia la administración creativa de las fronteras (Sassen, 1998, p. 37). Este doble movimiento, de destrucción creativa de las fronteras, por un lado, y de administración ventajosa, por el otro, se lleva a cabo por medio de dos mecanismos. Primero, por medio de la incorporación masiva a escala transnacional de mano de obra a los procesos de acumulación, lo que Marx ha denominado la subsunción real y formal del trabajo. En este proceso, los límites materiales, ideológicos y culturales (tales los prejuicios sexistas que previenen a las mujeres en ciertas sociedades su incorporación al trabajo asalariado, por ejemplo) que encuentra el capital en su tendencia a la acumulación son eliminados como condición necesaria para la incorporación de mano de obra en los procesos productivos, independientemente del espacio territorial donde estos ocurren. En esta primera forma, las fronteras nacionales no funcionan como barreras para el capital, sino como mecanismos que, al garantizar una división internacional de trabajo desigual, con naciones pobres, permiten la existencia de una reserva de mano de obra barata, dócil y siempre dispuesta a trabajar en condiciones óptimas para los empleadores, lo que garantiza 
la tasa de ganancia en capital acumulado, incluido capital humano (Sassen, 1998; Wallerstein, 2005; 2011 [1974]).

Segundo, la inflexión o destrucción creativa de las fronteras se lleva a cabo por medio de lo que David Harvey (2001, pp. 237-266) ha denominado "arreglos espaciales" (spatial fix); esto es, por medio de la expansión geográfica a través de 1) la relocalización y movilización de capital fijo, variable y mano de obra a nuevas regiones, 2) la apertura de nuevos mercados de consumo en otras geografías del sistema mundo como estrategias para superar crisis de acumulación, y a través de 3) la compresión del espacio/tiempo -o aniquilación de la distancia entre espacio y tiempo- apuntaladas por la permanente innovación tecnológica, incluyendo la innovación de las comunicaciones y la transportación (Harvey, 1989; 2003; 2010).

Finalmente, la sociedad civil —que puede ser definida como el espacio de las heterogéneas multitudes (Hardt y Negri 2004, p. XIV-XV)— está compuesta por un plural, multiforme y contradictorio conjunto de grupos sociales que disputan, como es el caso de los movimientos pro-migrantes y contra las fronteras, o reafirman, como es el caso de los movimientos xenofóbicos y anti-migrantes, las fronteras por medio de rituales culturales, movilidad, migración, la afirmación, la fuga, el escape o la protesta (Mezzadra, 2015). En la medida que la sociedad civil está compuesta por agentes heterogéneos, opuestos entre sí, con intereses divergentes, ésta se convierte en el espacio simbólico, ideológico, y material en el cual las fronteras, como reafirmadas y vigiladas por el poder soberano o como moldeadas por el capital, son reafirmadas, ritualizadas, reproducidas, interpretadas, cuestionadas, obedecidas 0 contestadas a través de las relaciones cotidianas entre los agentes sociales.

\section{Las fronteras del fordismo}

La fortaleza o la debilidad de las fronteras, así como su reforzamiento, administración, inflexión, o transformación, depende de la correlación o articulación de fuerzas que existe entre el capital, el Estado y la sociedad civil, así como del poder de influencia que cada una de estas instituciones tiene en el mundo social en un momento histórico particular. Teóricos del sistema mundo como Arrighi (2009), y con especial referencia a las fronteras, Mezzadra y Nielson (2013) han teorizado sobre la forma en que, durante el proceso de consolidación del capitalismo fordista, que ocurrió del momento de la posguerra hasta los años setenta, el Estado ocupaba la posición de liderazgo en la administración de las fronteras geopolíticas y en el diseño de los procesos de desarrollo y acumulación del capital (Mezzadra, 2015). En esta etapa, el Estado ejerció su soberanía estableciendo las reglas y condiciones 
sobre las cuales las mercancías, el capital y el trabajo son permitidas, o impedidas, de cruzar las fronteras. Para tales propósitos, el establecimiento de derechos de propiedad dentro del territorio soberano, las reglas relacionadas con el empleo y la compensación laboral, la regulación de la mano de obra nativa y extranjera, así como el control migratorio y la administración de la frontera ocuparon un papel central (Wallerstein, 2004, p. 46; Walsh, 2012).

Durante este periodo, la administración estatal de la frontera, y con ella la regulación de la circulación de mercancías, incluida la mano de obra extranjera como mercancía, la migración y la población, fue central para apuntalar el crecimiento económico. La incorporación de mano de obra migrante, clave para estos procesos de acumulación y desarrollo de sectores como la agricultura, se llevó a cabo principalmente a través de acuerdos bilaterales con países periféricos del sistema mundo. En muchos casos, como en Canadá, la selección de la mano de obra, así como su distribución en las áreas de producción, se llevó a cabo teniendo en cuenta criterios étnicos y raciales (Preibisch, 2007). La mano de obra extranjera era reclutada, incorporada, y puesta en circulación en la economía mundial y en los mercados laborales de los países centrales del sistema mundo a través de mecanismos jurídicos que, al importar tales trabajadores de forma diferenciada, reafirmaban la soberanía del Estado en asignar formas de inclusión desigual o inclusión diferenciada (Verduzco, 2015; Durand, 2015). La figura del "trabajador extranjero" ajeno al territorio administrado por el poder soberano estaba representada en términos raciales.

En los Estados Unidos, por ejemplo, millones de hombres (literalmente sólo hombres) mexicanos, indígenas y mestizos, fueron reclutados e incorporados como trabajadores migrantes de estatus temporal en la industria de la agricultura en California a través del Programa Bracero en los años sesenta. En Canadá, en la misma época, las políticas del Estado favorecieron la migración permanente trabajadores blancos, de origen europeo o norteamericano, a quienes se les ofrecía trabajo permanente, aun no siempre en las condiciones más favorables, mientras que las personas de piel negra fueron proscritos, literalmente, de emigrar y establecerse en Canadá. En 1966, se puso en marcha el primer programa de trabajadores agrícolas temporales (Seasonal Agricultural Workers Program) a través de un acuerdo bilateral con Jamaica. Como en los Estados Unidos con el Programa Bracero, en Canadá, los trabajadores temporales fueron incorporados sin derecho a beneficios asociados con la ciudadanía; esto es, sin derecho a seguro de desempleo; a la pensión de retiro, al voto, a cambiar de empleador, a la educación, entre otros (Basok, 2002,1999; Preibisch, 2007, 2015; Verduzco, 2015). 
Estas leyes que excluyeron a estos trabajadores temporales de ejercicios de ciudadanía ligadas al trabajo y a la residencia permanente crearon "fronteras internas" que impedían el pleno ejercicio de la ciudadanía entre las siguientes categorías legales de personas: 1) Trabajadores temporales; 2) Solicitantes de refugio, y 3 ) Indocumentados. Estas tres categorías de mano de obra extranjera, con excepción de los indocumentados, los excluidos de todo, tenían diferentes modalidades de acceso a derechos, pero de forma limitada (Goldring, Luin y Landolt, 2013; Verduzco, 2015).

Las fronteras en esa época, desde el punto de vista del trabajo, o las categorías de trabajadores realmente existentes, eran marginalmente polisémicas. Y ellas, al menos en los países centrales del sistema mundo, los llamados países receptores, eran relativamente estables, uniformes e inflexibles. En una alianza entre el Estado y el capital, las fronteras servían como mecanismos para la inclusión diferencial de trabajadores, garantizando la incorporación de una mano de obra barata, subordinada, sin derechos plenos, necesaria para apuntalar los procesos de acumulación en un periodo (la posguerra) en el cual se requería fortalecer los procesos de desarrollo y acumulación "hacia adentro" (Sassen, 1998; Wallerstein, 2005; 2011 [1974]).

La incorporación masiva de mano de obra migrante generó tensiones entre trabajadores nativos y migrantes, divisiones y tensiones que a menudo adquirieron un carácter racial. A pesar de ello, este modelo de incorporación masiva de trabajadores migrantes durante el capitalismo fordista hizo posible las alianzas obreras (Ganz, 2015). De la misma manera, se puede decir que aunque los mercados laborales se segmentaron en función de criterios raciales y étnicos -creando con ello las bases de sociedades jerárquicamente desiguales donde los trabajadores racializados ocuparon las posiciones más subordinadas y en desventaja como lo describe el famoso libro El Mosaico Vertical del sociólogo canadiense John Porter (1970)-, las organizaciones de trabajadores, movimientos por los derechos de los trabajadores y sindicatos, lograran establecer alianzas entre los trabajadores migrantes (denizens con derechos parciales) y los trabajadores locales (ciudadanos con derechos plenos).

La historia de las luchas por los derechos laborales en Estados Unidos y Canadá Ilevada a cabo por el United Farm Workrs of America, UCF, Industrial Workers of the World en los Estados Unidos, y el Union for Agricultural Workers y el Agricultural Workers Alliance, está llena de estos ejemplos de alianza entre trabajadores de distintos orígenes étnicos y estatus migratorios con los trabajadores locales (Ganz, 2009). Parece ser que la relativa inflexibilidad de las fronteras durante el periodo fordista permitió la unificación del trabajo contra el capital y contra la exclusión. Esto ocurrió a través de la existencia de bloques y alianzas migrantes de 
indocumentados, refugiados y trabajadores nativos, para quienes la frontera tenía un significado más o menos similar, al menos no tan antagónico.

\section{Las fronteras del neoliberalismo}

La operación de las fronteras ha cambiado el marco de la implementación del modelo económico neoliberal que se puso en marcha en el mundo después de los años ochenta. Durante esta época, la relativa inflexibilidad e impermeabilidad de las fronteras tuteladas, reforzadas y vigiladas por el poder soberano sufrió una importante transformación. Como ya ha sido discutido por influyentes pensadores de la globalización, el neo-imperialismo, y del sistema mundo (Arrighi, 2009; Harvey, 2008; Sassen, 2014; Wallerstein, 2010), en esta época el capital, liderado por su fracción financiera, emprendió un proceso de expansión territorial, todo a expensas de una subordinación parcial de la soberanía del Estado.

Las fronteras geográficas, antes herméticas y rígidamente administradas por el Estado, se flexibilizaron, aún de forma parcial. Las formas de regulación del trabajo y los flujos migratorios, antes elaborados con el propósito de apuntalar procesos locales de crecimiento del mercado interno, fueron transformadas para satisfacer las necesidades de las corporaciones por hacerse de mano de obra barata, flexible, y subordinada en diversas regiones del mundo, mucho en función de una nueva tendencia expansionista a escala transnacional (Durand, 2015). En los países centrales del sistema mundo, incluidos aquellos países que no siendo hegemónicos política y militarmente pero que ocuparon un lugar de liderazgo en el sistema mundial, tales como Canadá, Australia, entre otros, los Estados implementaron una variedad extraordinaria de programas para facilitar de importación de mano de obra "extranjera" calificada y no calificada, proveniente de diversas regiones del mundo. A través de esta variedad de programas, trabajadores temporales de diversas categorías (altamente calificados, semicualificados, no calificados) regulados bajo diferentes regímenes jurídicos, así como diversos acuerdos bilaterales con diferentes países del mundo, fueron incorporados en forma igual diversa y estratificada en los mercados de trabajo locales.

Por su parte, los países periféricos del sistema mundo, como los países del sur de Asia, de América Latina, de África del Norte, entre otros, llevaron a cabo procesos de desregulación laboral y desmantelamiento parcial de los derechos de los trabajadores, bajo el mantra de "incentivar la inversión extranjera directa”. Los millones de trabajadores desplazados de los mercados laborales locales, las poblaciones excedentes del capitalismo global, incluidos trabajadores calificados y no califica- 
dos en el campo y la ciudad, fueron incorporados a través de acuerdos bilaterales con los países demandantes de mano de obra en condiciones de desprotección y desventaja. Las instituciones internacionales, como la Organización Internacional para las Migraciones, incentivaron estos acuerdos señalándolos como situaciones donde todo mundo gana, "a win-win situation".

Este doble movimiento, que facilitó la incorporación a los trabajadores "excedentes" o desposeídos del sur del mundo en los mercados laborales en el norte del mundo bajo diversas formas de regulación laboral (trabajadores temporales calificados; trabajadores temporales no calificados; trabajadores domésticos temporales; trabajadores agrícolas temporales en esquema de dos años o de un año, etc), generó lo que Mezzadra y Neilson (2013) han denominado la "multiplicación del trabajo"; esto es, generó la súbita aparición de una multiplicidad de figuras del trabajo incorporadas a lo largo y ancho de los mercados laborales en el sistema mundo bajo diferentes categorías, temporalidades, salarios, con sus concomitantes diferencias en términos de posiciones de clase e intereses (Mezzadra, 2019).

La multiplicación de trabajo implicó también la multiplicación o "proliferación de las fronteras." Éstas no solo se volvieron "flexibles" sino que también se volvieron polisémicas, ya que en un mismo espacio social diversos tipos de trabajadores tienen permitidas diferentes formas de habitar el territorio. La flexibilización de las fronteras por el capital en la época neoliberal volvió porosas y flexibles, polisémicas y múltiples, las líneas de demarcación territorial, y generó al mismo tiempo una recomposición de la mano de obra migrante organizada en la forma de una jerárquica división del trabajo, donde las y los trabajadores quedaron divididos por el estatus migratorio. Como consecuencia, en un mismo campo agrícola, por ejemplo, del sur de Ontario, o en una misma fabrica en Montreal trabajan juntos migrantes temporales legales provenientes de Guatemala o México con trabajadores migrantes altamente calificados provenientes distintos países de Europa o África, trabajadores indocumentados provenientes de diferentes países periféricos, así como trabajadores ciudadanos locales, los cuales también están divididos por sus habilidades técnicas; escalas salariales, etnicidades, género, estatus legales, incluidos estatus legales precarios (así definidos por Goldring y Landolt, 2013), modalidades de vivir la "deportabilidad" (Basok, et. al., 2014), derechos, y acceso desigual a tales derechos.

La multiplicidad del trabajo en el neoliberalismo, para continuar la lógica argumentativa de Mezzadra y Neilson (2013), creó una proliferación de las fronteras, así como múltiples obstáculos entre los trabajadores migrantes en el norte del mundo para constituir bloques de resistencia a las fronteras de la exclusión. 


\section{Los muros en todas partes: covid-19 y la proliferación de las fronteras en Canadá}

La disrupción mundial generada por el covid-19 ha cambiado esta situación. Las fronteras geográficas externas se volvieron más herméticas y selectivas cuando se trata de permitir la circulación de mercancías, incluida la mano de obra migrante. En Canadá, por ejemplo, durante la primavera de 2020, el número de trabajadores temporales que cada año son incorporados a los campos agrícolas canadienses disminuyó drásticamente o experimentó "retrasos", generando una crisis de mano de obra a nivel local, tanto en la agricultura como en general en la industria de los alimentos (Sheldon, 2020). Diversas modalidades de solicitud de refugio de quienes llegan por tierra desde los Estados Unidos fueron suspendidas (Canadian Council for Refugees, 2020). El tránsito y la movilidad humana tanto de forma interna entre provincias, como a nivel internacional se redujeron también de manera significativa.

De la misma forma, las "fronteras internas" se multiplicaron e intensificaron en el contexto del covid-19. Las y los migrantes indocumentados, los llamados "sans papiers," perdieron sus empleos, o sus horas de trabajo se redujeron drásticamente (hasta un 50\%, en promedio, según las narrativas de los trabajadores indocumentados con quien he convivido); la puesta en práctica de toques de queda en Quebec, que implicó mayor presencia policiaca en las calles vigilando la disciplina social con respecto la distancia social y la cuarentena preventiva, redujeron la experiencia social de las y los indocumentados y otros migrantes de estatus legal precario, a una vida en aislamiento casi total. El acceso a los servicios de salud, los exámenes de covid y las vacunas se volvieron espacios a evitar para muchos de los indocumentados, quienes evitaban estos espacios por temor a ser deportados. La deportabilidad, entendida como la experiencia subjetiva y objetiva que estructura la disciplina y subordinación en la vida cotidiana de los indocumentados por medio del temor a ser atrapados y deportados (De Genova, 2002), se intensificó como resultado de la multiplicación de las fronteras, internas y externas, en el contexto del covid-19.

Las mismas políticas "universales" de apoyo financiero que han sido benéficas para la población con estatus legal han traído como consecuencia la intensificación y proliferación de las fronteras, afectando principalmente las poblaciones de migrantes indocumentados. El llamado Canada Emergency Response Benefit -CERB- (Beneficio Canadiense de Respuesta de Emergencia), por ejemplo, un programa gubernamental que proveyó con 2 mil dólares mensuales a los residentes canadienses empleados y auto-empleados que fueron directamente afectados por el covid-19, excluyó a quienes trabajan y habitan de manera “ilegal” en el territorio. 
De la misma forma, el seguro de desempleo, al que tienen acceso los ciudadanos y residentes de Canadá, les fue negado a las poblaciones de indocumentados, a pesar de que estas poblaciones contribuyen con su trabajo de forma importante a sectores claves de la economía.

Todas estas medidas de apoyo en el marco de la emergencia sanitaria, que exceptúan a las poblaciones indocumentadas, han generado por un lado que el carácter excluyente de la frontera, que distingue entre seres humanos que son tutelares de derechos asociados a la ciudadanía de aquellos que no son tutelares de tales derechos, se fortalezca, se extienda y se multiplique. En el marco de la pandemia, los migrantes indocumentados, fueron conscientes de forma mucho más clara, y en el contexto de crisis y peligro literal de enfermedad y muerte, que la frontera no es solamente esa línea que demarca los límites de la región y comunidad política de la cual han sido proscritos, y marginados. Ser excluidos de todo apoyo institucional hizo visible, quizá más que nunca, que la frontera está en todas partes. La frontera aparece allí en el hospital donde temen acercarse para buscar servicios de salud. La frontera está también en el trabajo donde se les niega el derecho a las prestaciones esenciales ligadas al empleo, o al desempleo temporal. La frontera está allí en las ventanillas de los bancos de comida, donde para tener acceso a tales apoyos, se les requiere una identificación oficial, la cual muchos indocumentados no tienen. La frontera apareció en todas partes, se hizo presente todos los días, recordándoles que ellos son extranjeros ilegales, que han sido proscritos de su derecho de pertenencia a la comunidad política y social y cultural que han elegido para vivir, trabajar y reproducirse como seres humanos. $\mathrm{Y}$ que, por lo tanto, no tienen derecho a ser tratados como ciudadanos, con los derechos que están asociados con esta categoría política.

\section{Insurgencias migrantes en Canadá: solidaridad, refugio y políticas de vida}

Pero las formas de exclusión creadas por la multiplicación de las fronteras han generado un contra movimiento que tiene importantes implicaciones sociales y políticas. Frente a esta situación, las poblaciones excluidas, principalmente los migrantes indocumentados y otras poblaciones de estatus precario, con el apoyo de otras organizaciones sociales canadienses, se han movilizado políticamente para exigir el estatus legal universal ("Estatus Legal para Todos/as"), y para brindar protección y refugio de emergencia hacia quienes han sido excluidos en el contexto de la pandemia. Esto ha dado origen a la emergencia de una multiplicación de las luchas contra las fronteras. Organizaciones como Solidaridad sin Fronteras y la 
red nacional Migrant Rights Network, quizá las redes más densas y extendidas de individuos y organismos que luchan por el reconocimiento de los derechos de las poblaciones indocumentadas y los migrantes de estatus precario en Canadá, han Estado llevando a cabo tanto en el campo como en la ciudad una serie de acciones que han creado las posibilidades para la emergencia de un nuevo sujeto político que no solo ha establecido grietas en las fronteras de la exclusión, como se discutirá más tarde, sino que también ha reinventado saberes y prácticas políticas que tienen un alcance social más amplio. A continuación, se describe brevemente este tipo de movilizaciones y sus implicaciones.

\section{Figura 1}

"Rompiendo fronteras" "Rompiendo Barreras"

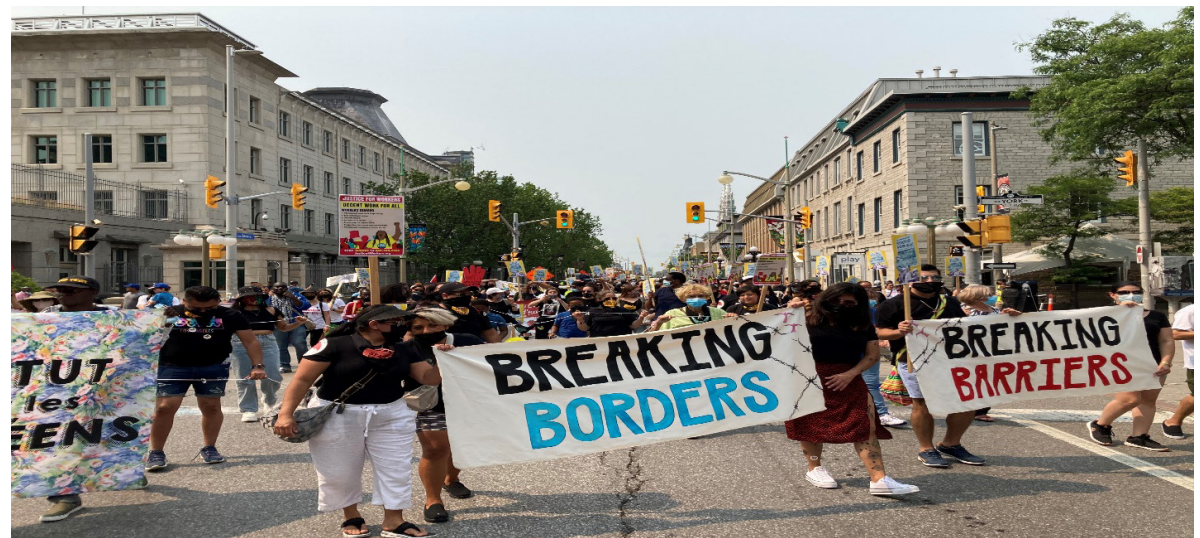

Nota: Migrantes indocumentados y organizaciones aliadas provenientes de Montreal, Toronto y Ottawa organizaron una marcha-caravana histórica en agosto de 2021. Diversas caravanas provenientes de estas tres ciudades, así como de comunidades rurales, se encontraron en Ottawa para demandar al Estado canadiense la implementación de un programa completo de regularización del estatus legal de cientos de miles de inmigrantes que viven en territorio canadiense en condición de "ilegales". Fotografía: Eloy Rivas-Sánchez

a. Refugio, solidaridad y grietas en las fronteras. En las principales metrópolis canadienses, como Montreal, Toronto y Vancouver, estas organizaciones han llevado a cabo recolectas de dinero, comida y otros esenciales entre la población general. Estos bienes se distribuyen entre aquellos que tienen dificultad para comprar comida, para pagar la renta de la vivienda y los gastos asociados (energía eléctrica, gas, teléfono, internet y otros gastos familiares). Además, tales organizaciones han elaborado campañas legales y políticas para poner en libertad a los migrantes que se encuentran recluidos en los centros de deportación de jurisdicción federal, 
literalmente cárceles donde el Estado canadiense recluye a los indocumentados detenidos antes de ser deportados. En Montreal, la campaña \#FreeThemAll \#HungerStrike Laval organizada por Solidarité sans Frontieres, -la cual consistió en la organización de caravanas de autos entre abril y mayo de 2020 que protestaban periódicamente frente al centro federal de detención y vigilancia de la migración localizada en Laval, Quebec - , logró la liberación condicional del total de migrantes irregulares que se encontraban detenidos en el desde antes de la irrupción del covid-19. Esta campaña logró que tales migrantes detenidos, incluyendo niños y familias, fuesen liberados de forma condicional, y aseguró la creación de una red amplia de solidaridad entre los ciudadanos que proveyó a los ex detenidos de vivienda, alimentación y apoyo financiero mientras llevaban a cabo los litigios legales para obtener su liberación definitiva.

\section{Figura 2}

"ACTÚA AHORA! Detenidos-as en Huelga de Hambre en la Prisión para Migrantes de Laval

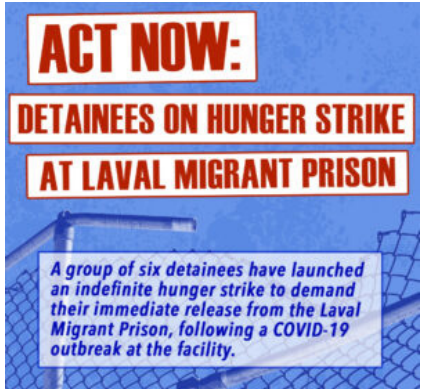

Nota: Un grupo de 6 detenidos han comenzado una huelga de hambre indefinida demandando su inmediata liberación de la Prisión para Migrantes de Laval, después de la crisis de salud que se generó en esa prisión debido a los casos de covid" Fuente: Archivo digital de Solidarité Sans Frontieres

\section{Figura 3}

"Liberar a los sin papeles de la esclavitud" "Permanente y completo estatus permanente para todos-as"

Nota: Migrantes indocumentados provenientes de distintas partes del mundo protestan en el Parlamento de Canadá y demandan un plan de regularización migratorio permanente y completo. Julio de 2021. Fo-

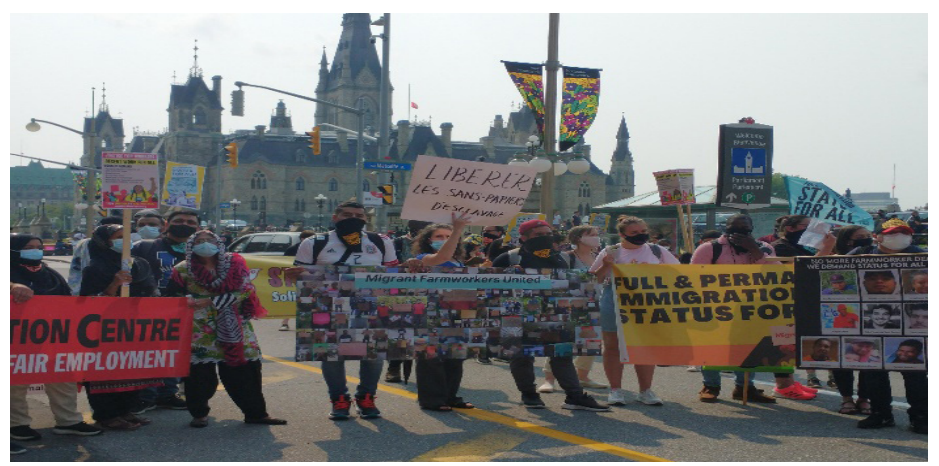
tografía: Eloy Rivas-Sánchez 


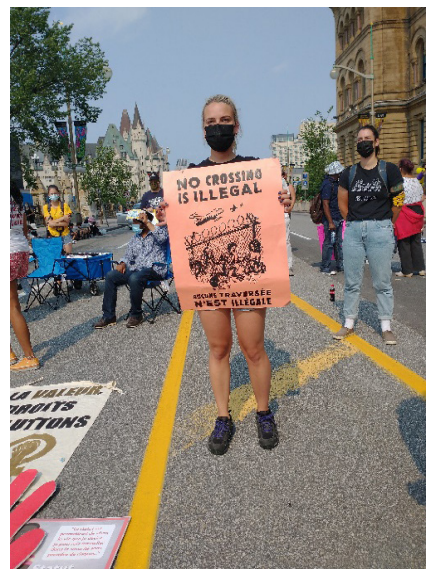

\section{Figura 4}

Ningún Cruce [fronterizo] es llegal

Nota: Protesta en el Parlamento de Canadá. Ottawa, Canadá, Julio de 2021.

En las comunidades rurales, organizaciones filiales a organizaciones de Toronto como Justice 4 Migrant Workers and Migrant Rights Network, han creado comités de apoyo que ofrecen solidaridad y refugio para las y los migrantes de estatus precario que han sido dejados sin apoyo institucional en el contexto de la pandemia debido a su estatus legal irregular. En varias comunidades del sur de Ontario, por ejemplo, redes de ciudadanos canadienses, compuestas notablemente por médicos, ministros de culto de iglesias de culto, profesores, psicólogos, trabajadores sociales, estudiantes y otros públicos, han establecido paquetes de apoyo de emergencia para estas poblaciones. Algunos propietarios de granjas agrícolas locales que pro-

\section{Figura 5}
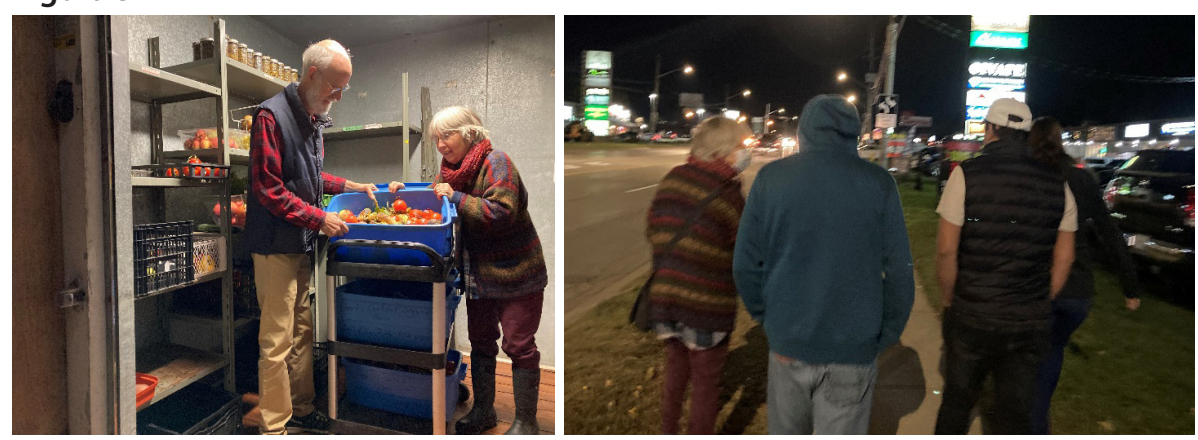

Nota: Ella y Richard, dos profesores universitarios retirados, recolectan comida en un cuarto refrigerado que luego entregan a los migrantes mexicanos que habitan y trabajan cerca de su comunidad, una comunidad rural en el sur de Ontario. En su granja orgánica, ofrecen clases de inglés, proveen techo y comida a quienes no tienen donde vivir. Con frecuencia, los trabajadores temporales que son expulsados de los programas temporales de trabajo se quedan sin vivienda y sin ingresos financieros. La granja de Ella y Richard es un espacio de refugio para todos estos migrantes de estatus precario en busca de asilo. Fotografía: Eloy Rivas-Sánchez 
ducen vegetales orgánicos elaboran paquetes de despensa semanal, mismos que son distribuidos entre los trabajadores temporales que han perdido su trabajo y, por tanto, enfrentaron inseguridad alimenticia durante la pandemia. Estas despensas incluyen no sólo vegetales y otros víveres necesarios para la seguridad alimentaria, sino también dinero en efectivo, apoyo psicológico gratuito, trámites legales, y visitas periódicas a través del cual se les provee de compañía y apoyo moral en momentos de asilamiento y desesperanza. (Foto 5)

Además de estos trabajos cotidianos, en el campo y la ciudad, para ayudar a los migrantes de estatus precarios afectados por las fronteras de la exclusión en el contexto del covid-19, estas organizaciones de ciudadanos, y organizaciones de indocumentados en sí mismos, han llevado a cabo movilizaciones importantes que demandan al Estado canadiense que les brinde estatus legal y amnistía para todos los residentes que viven indocumentados en Canadá. De acuerdo con mi registro etnográfico, en Montreal, donde se ha llevado a cabo un mayor número de demostraciones políticas en apoyo a las poblaciones migrantes de estatus precario, desde abril de 2020 hasta noviembre de 2021, se han llevado a cabo más de 35 demostraciones políticas, muchas de ellas masivas, en apoyo a las poblaciones de estatus migratorio precario que han sido afectadas por la pandemia. Los infantes que dan la bienvenida a los migrantes precarios está presente en estas marchas.

\section{Figura 6}

Viva la solidaridad con las/os sin papeles: Saboteemos la máquina de expulsión.

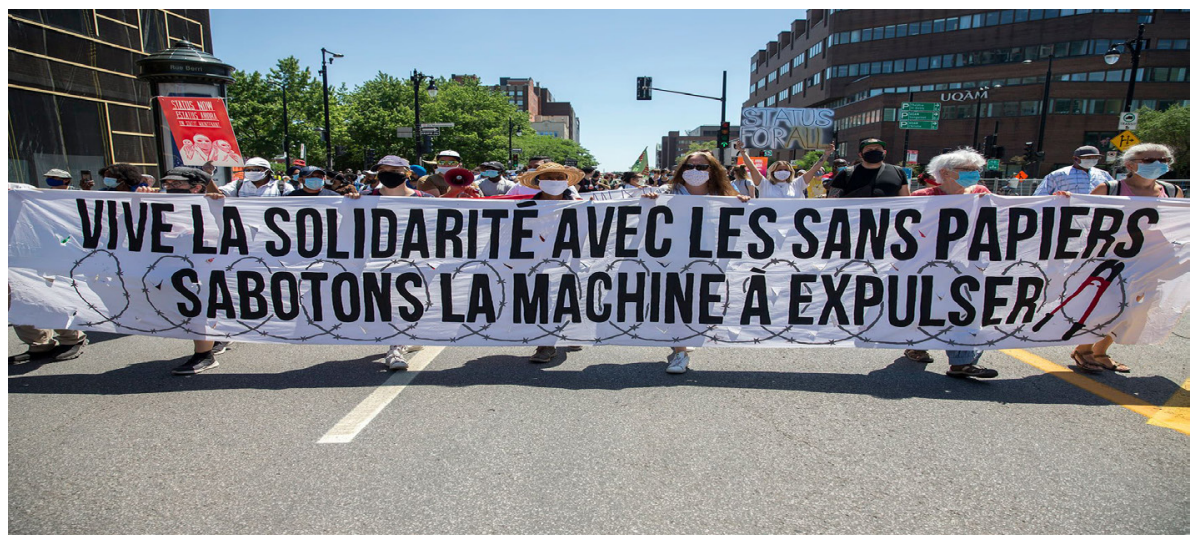

Nota: Montreal, Canadá, Junio de 2020.

b) La proliferación de las luchas y la emergencia de un nuevo sujeto político. Un asunto importante para destacar es que tales formas de acción solidaria, in- 
cluidas las movilizaciones por demandar estatus legal para los indocumentados y otros migrantes de estatus legal precario, han logrado articular una alianza entre diversos sectores de la población. Grupos sociales muy diversos, compuestos por refugiados, ex prisioneros estudiantes internacionales, activistas queer, trabajadores temporales, migrantes indocumentados, e incluso organizaciones que no están directamente relacionadas con la justicia migrante, tales como los movimientos estudiantiles, los movimientos feministas, los sindicatos obreros, organizaciones antirracistas, profesionales de la salud y la educación, entre otros, elaboran en esfuerzos conjuntos en campañas políticas de solidaridad hacia las y los migrantes irregulares "abandonados" en el contexto de pandemia. Estas acciones colectivas demandan la inclusión de los migrantes precarios, y exigen la implementación de estatus legal para todos los migrantes sin estatus legal.

El valor de estas movilizaciones no se limita al hecho de brindar seguridad económica, salud y refugio a los migrantes indocumentados, y al hecho que han logrado la libertad y desencarcelamiento de los detenidos en los centros de deportación. Esas luchas también han conseguido la emergencia de los indocumentados como nuevo sujeto político. Esto se ha logrado por medio de la rearticulación de las luchas contra la propagación de las fronteras de la exclusión, a través del enlazamiento de grupos de trabajadores migrantes que antes se encontraban divididos y jerarquizados por las políticas migratorias del periodo neoliberal y la "proliferación del trabajo" (y multiplicación de las fronteras) que este trajo consigo. Indocumentados, refugiados, residentes permanentes, trabajadores manuales, trabajadores intelectuales, empleados y desempleados, estudiantes, profesores, trabajadores de la salud, han convergido en estas luchas, creando una autentica infraestructura del disenso que disputan las fronteras de la exclusión, que somo se ha dicho, se han multiplicado aún más en el contexto del covid-19.

Estos espacios de lucha, de manera tal vez paradójica, han establecido grietas en tales fronteras, líneas de fuga; han generado lazos de unión entre luchas anteriormente separadas, y prácticas colectivas de resistencia y solidaridad que atraviesan las fronteras de clase, y de género, y de estatus legal migratorio. También han generado formas de inclusión, de apoyo mutuo, y la solidaridad que incluyen de manera radical a los grupos de migrantes más afectados por la proliferación de las fronteras del periodo neoliberal. Tales grietas en la frontera de la exclusión, además de formas de inclusión radical, al margen y en contraposición de la exclusión estatal, han generado la emergencia de un sujeto político que pugna por formas de solidaridad universalista. Ese sujeto político es rizomático y nómada en el sentido Deleuziano del término (Deleuze \& Guattari,2009), así como diverso, multicolor y 
multilingüe. Podría ser representado por una niña/niño de mirada tierna, multilingüe, descendiente de una mujer blanca y un hombre mestizo latinoamericano que llega a las marchas con una pancarta que dice:"Bienvenido todo el mundo. Mi casa es tu casa. Estatus para tod@s!" O en una mujer racializada, indocumentada que atiende marchas y organiza traduciendo en varias lenguas para que sus camaradas se comuniquen y se entiendan entre sí. Este nuevo sujeto político puede estar representado también en la imagen de una mujer blanca, profesora universitaria, que estudia, conoce, se involucra con los desposeídos, a pesar de que ella no es uno de ellos. 0 en la imagen de un hombre árabe, o africano, que sabe mucho, porque ha recorrido el mundo, pero que no es reconocido y pasa sus días batiéndose en la fábrica, siendo explotado, para vivir día a día. También puede ser representado en la imagen de un biker de clase media, con estudios universitarios, ambientalista, internacionalista, anarquista y soñador que respeta a los indocumentados, quienes son sus compañeros de trabajo. La imagen de este sujeto político parece ser la imagen de una multitud diversa, rizomórfica, que cruza fronteras y se comunica.

\section{Figura 7}

Estatus legal para Todos/as

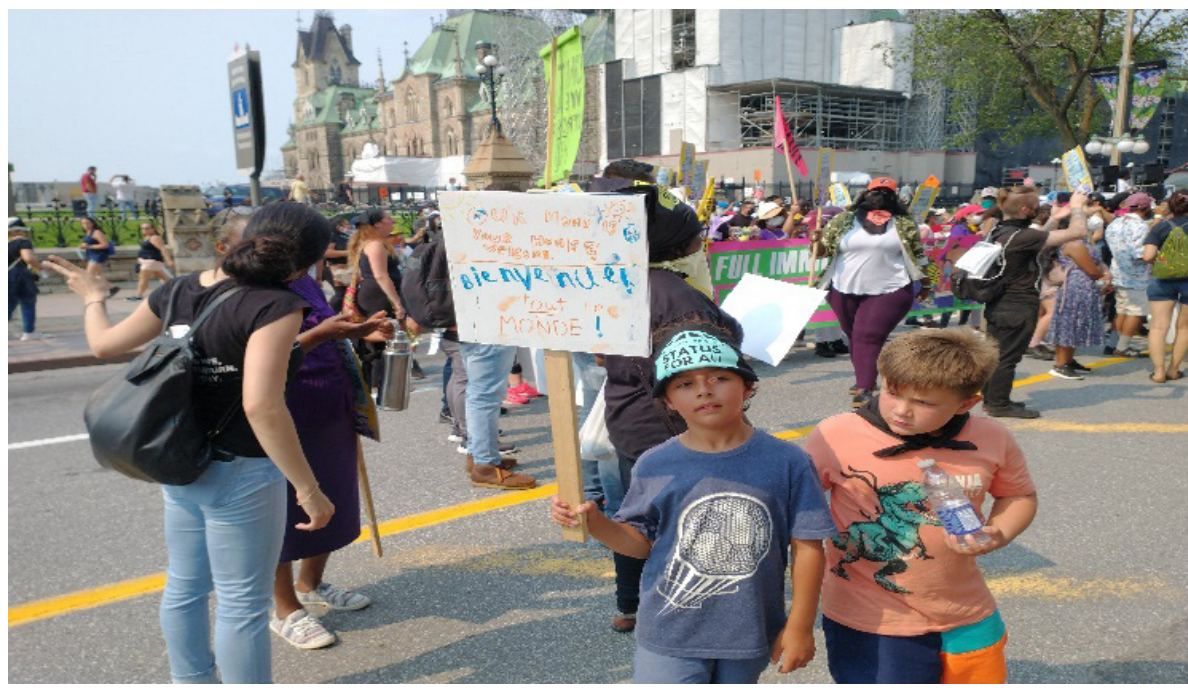

Nota: Niños, hijos de hombres latinoamericanos de primera generación y madres canadienses, participan en la manifestación. En la pancarta, elaborada por ellos mismos, dice:"Bienvenido todo el mundo. Mi casa es tu casa. Estatus para tod@s!" Ottawa, Canadá, Julio de 2021. Fotografía: Eloy Rivas-Sánchez 
Figura 8

Estatus Legal para todos/as. Solidaridad sin Fronteras

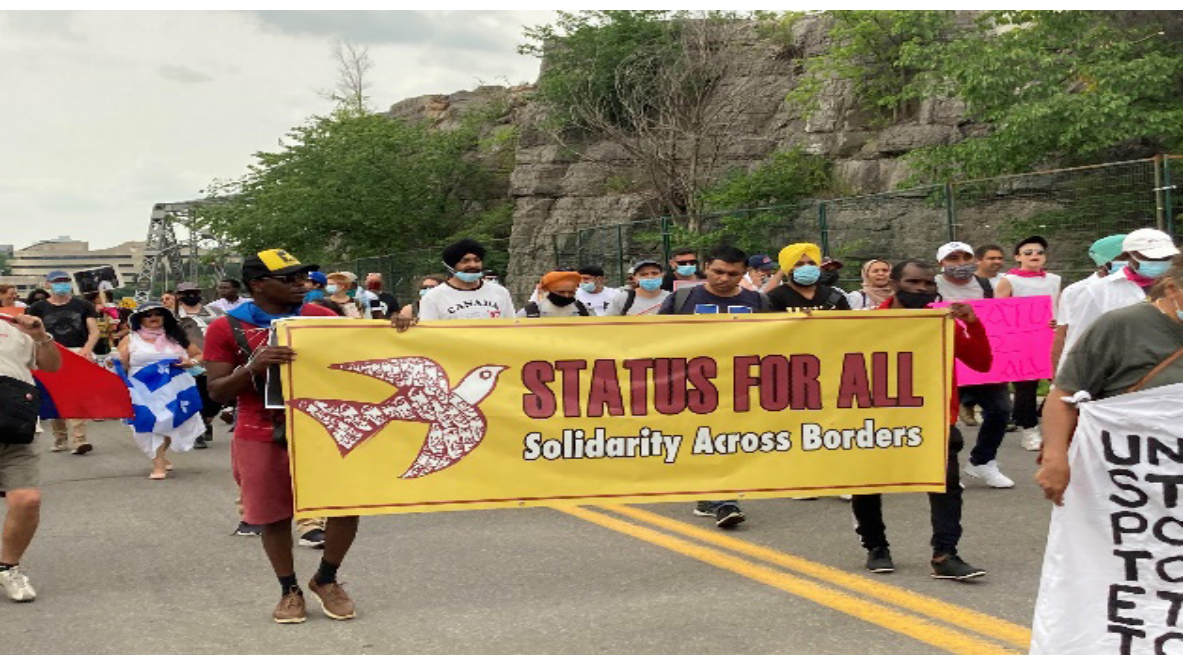

Nota: Hombres y mujeres de una variedad de orígenes étnicos, caminan en la caravana MontrealOttawa. La caravana, demandando "estatus legal para todos/as" comenzó el 18 de Julio en Montreal, recorrió 270 kilómetros, y concluyó en Ottawa el día 25 de Julio. Esta caravana incluyó actividades políticas, asambleas, y actividades lúdicas. Las mujeres jugaron un papel central en la organización del evento, así como traducción cultural y lingüística entra los más de 20 idiomas que se hablaban entre las y los participantes, provenientes de más de 40 orígenes étnicos. Fotografía: Eloy Rivas-Sánchez

c) La centralidad de la vida en las luchas contra la multiplicación de las fronteras. Quizá la consecuencia más importante es el hecho de que estas movilizaciones de lucha contra las fronteras de la exclusión han colocado la protección de la vida en el centro.

La multiplicación de las fronteras de la exclusión en el marco del covid-19, y la exclusión de que han sido sujetos por parte de las instituciones los migrantes de estatus precario, tal y como se ha documentado hasta el momento, tienen como consecuencia la muerte social de tales poblaciones, y así como a veces también la muerte física. No tener acceso a apoyos financieros, a techo, comida y salud en tiempos del covid genera lo que se ha denominado la "muerte social." La muerte social, tal como lo ha teorizado Honneth (1997) ocurre como consecuencia del desreconocimiento y la falta de respeto al estatus moral de individuos y comunidades que son excluidos en virtud de poseer un estatus socialmente estigmatizado. La muerte social ocurre porque los individuos y grupos sociales que son sujetos de des-reconocimiento están expuesto al desarrollo de un déficit en sus nociones de auto-respeto y valía de sí mismos, una concepción distorsionada de sí mismos, 
así como una denigración de sus formas de vida, todo lo cual puede llevarlos al colapso sicológico o a su "muerte social" (169). En el contexto del covid, la muerte social de los trabajadores migrantes de estatus precario ocurre por medio de dos mecanismos: 1) por medio de la exclusión social y el desreconocimiento del derecho fundamental que tienen estas comunidades a ser reconocidas, incluidas y protegidas en contextos de precariedad radical y peligro de muerte, y 2) también como consecuencia de estar siendo sometidos a políticas de desprotección y deportabilidad que ponen en peligro su salud mental y su salud física en el contexto de una crisis mundial de salud.

La desprotección en este contexto de crisis sanitaria y económica, y de aislamiento y distancia social, genera la muerte física del sujeto. Desde el inicio de la pandemia, hasta el momento, ha sido documentada la muerte de al menos una docena de trabajadores migrantes temporales empleados en granjas agrícolas canadienses. De igual forma, en 2020 se contabilizaron 1,780 casos positivos al covid sólo en la provincia de Ontario (Faraday, 2021).

Entonces, las luchas que se describieron en los apartados anteriores, están enfocadas en garantizar que las poblaciones excluidas en el marco del covid-19 puedan tener acceso a las condiciones objetivas (acceso a salud, vivienda, comida) y subjetivas (reconocimiento, apoyo moral) para la supervivencia en contextos de exclusión radical y peligro inminente a la vida e integridad son luchas que tienen como objeto la protección de la vida humana.

Las luchas por la protección de la vida que inauguran estas organizaciones, a las que nos hemos referido, son diferentes de las biopolíticas que Foucault (2003) definió como el conjunto de prácticas disciplinarias, semi-fascistas orientadas a la administración de la vida por medio de dispositivos de poder institucionales y discursivos, mismas que son fundantes de las instituciones modernas (tales como la prisión, la cárcel, el hospital psiquiátrico). Por el contrario, las políticas de vida inauguradas y recreadas por las luchas entrelazadas de los "sin papeles", los trabajadores de estatus legal precario, y las organizaciones políticas aliadas, parecen practicar una política que está fundada en una ética del reconocimiento profundo de los seres humanos. Con esto, las luchas parecen estar inaugurando un retorno a la política en su sentido más estricto. Esto es, en la medida en que estas luchas buscan garantizar el acceso de las y los indocumentados a la salud universal, al bienestar, a la solidaridad, al reconocimiento moral y legal, a las condiciones materiales y simbólicas esenciales para la protección y reproducción de la vida, y también en la medida que estas luchas buscan la inclusión de aquellas personas proscritas y negadas del reconocimiento por las fronteras de la exclusión, estas luchas de los "sin papeles" 
se adhieren al principio y contenido fundamental de toda política emancipatoria, que en las palabras del profesor Enrique Dussel, buscan, sobre todo,"la protección y prolongación cualitativa de la vida," así como"la afirmación y el avance de la vida, de la comunidad, de la gente, y de la humanidad (Dussel, 2015, p.61).

\section{Figura 9}

Para todo mundo un estatus [legal]. Para todo mundo TODO

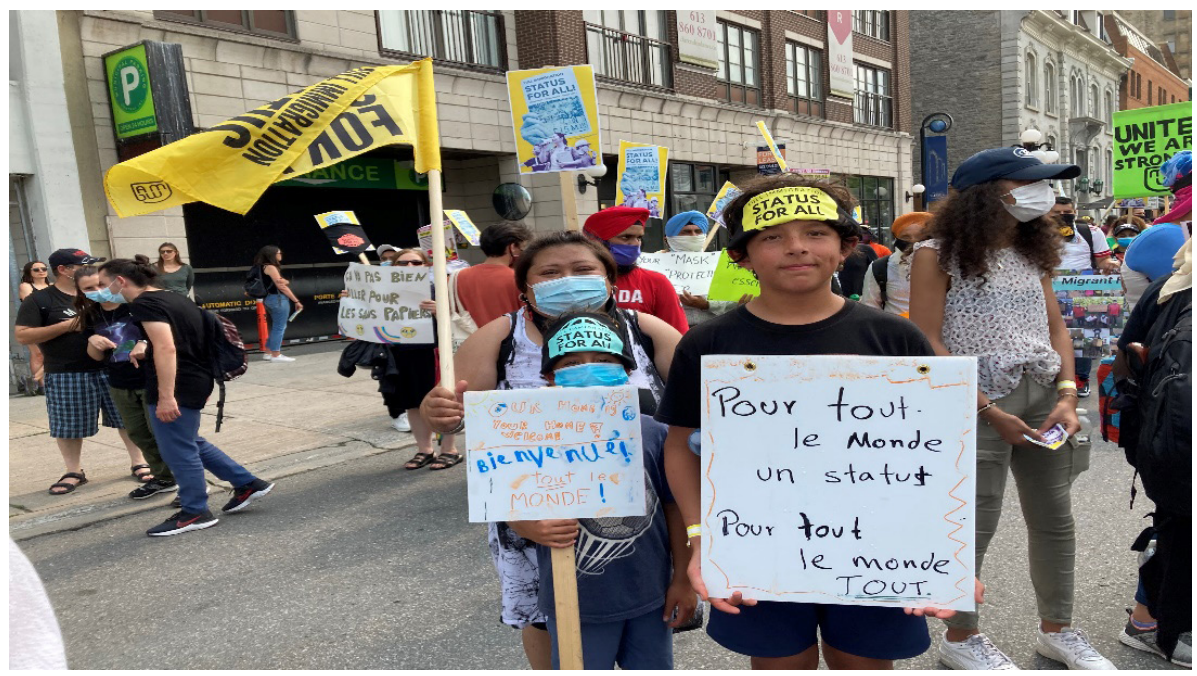

Nota: Mujer Filipina, trabajadora doméstica y de cuidados, y dos niños, participan en la caravana "Estatus para Todos/as" en el verano de 2021. Organizada por más de 20 organizaciones de justicia migrante, incluidas Solidarity Across Borders y Migrant Rights Network, en el contexto de la emergencia sanitaria del Covid, esta marcha exigía al gobierno canadiense la inclusión de las comunidades de indocumentados en los planes de apoyo humanitario y la regularización legal de más de 500 mil indocumentados que viven y trabajan en Canadá sin permiso legal. Otawa, Canada, Julio de 2021

¿Cuáles son algunas de las implicaciones de estas luchas por la protección de la vida en el mundo actual? A manera de hipótesis, me gustaría destacar algunas de estas.

1. Inauguran una rebelión contra la necropolítica. Como sabemos, el neoliberalismo inauguró y expandió por el mundo un conjunto de políticas y fronteras simbólicas fundadas en lo que Aquille Membde (2019) denominó las políticas de muerte o necropolíticas. Tal como son descritas por este autor, estas políticas que implementan los grupos sociales hegemónicos para dictar qué personas tienen derecho a vivir y qué personas son expuestas a la muerte en el marco de un 
territorio y una frontera determinada, aún siguen vigentes. De hecho, como se ha descrito de forma sucinta en las páginas anteriores, los indocumentados y otros migrantes de estatus en Canadá están siendo excluidos de los beneficios sociales implementados por el Estado canadiense para proteger a las y los ciudadanos de los efectos destructivos del covid. Desde este punto de vista no es exagerado decir que los indocumentados son los únicos sujetos sociales abandonados al riesgo de muerte en el territorio canadiense.

Entendido de esta forma, no es exagerado argumentar que las luchas de las y los "sin papeles", cuyo énfasis es la protección y prolongación cualitativa de la vida humana, contestan estas políticas de muerte. Al poner en el centro de su acción política la protección de la vida de los no ciudadanos que han sido excluidos y expuestos al riesgo de muerte, incluida la muerte social, están inaugurando una nueva forma de pensar y hacer la política. Por lo cual, las fronteras de la exclusión son contestadas, los territorios adquieren un significado universalista, y de inclusión. Las fronteras son atravesadas, contestadas, resignificadas y habitadas de otra manera. De la misma forma, la solidaridad internacional, sin fronteras, es revivida, y las representaciones sociales que dictan quienes tienen derecho a pertenecer a un territorio y quien debe ser expulsado, quienes son proscritos de tal territorio, o quienes tienen derecho a ser protegidos controla muerte y quienes son excluidos de la misma, base de la necropolítica en el capitalismo avanzado, son igualmente contestadas, resistidas y transgredidas.

2. La construcción de comunidades políticas universalistas. La multiplicación del trabajo en el capitalismo avanzado en los países centrales del sistema mundo y que, por medio de la intensificación del trabajo y la jerarquización de la mano de obra migrante en función del estatus legal, calificaciones laborales, raza y género, como he señalado anteriormente, hizo proliferar las fronteras de la exclusión de los trabajadores migrantes de estatus precario, subyugó parcialmente la resistencia y la acción colectiva entre estas poblaciones. Durante mucho tiempo, esta situación hizo difícil la construcción de alianzas políticas entre diferentes movimientos sociales atomizados, e hizo difícil que tales comunidades políticas, sin sujeto emancipatorio definido, se apropian del espacio y el territorio de una forma universalista, más allá de las fronteras simbólicas y materiales que impuso el nuevo orden social neoliberal. Estas divisiones, atomizaciones, y líneas de demarcación que separaron a grupos sociales entre sí, y excluyeron a los migrantes precarios de privilegios y derechos asociados a la ciudadanía, está siendo contestada. Los migrantes indocumentados, así como los migrantes de estatus legal precario, aunque no del todo emancipa- 
dos del aislamiento y la disciplina impuesta por el miedo a la deportación, en el contexto del covid-19 parecen empezar a componer una multitud, heterogénea pero menos fragmentada, de migrantes diversos de estatus precario, y sus organizaciones y movimientos sociales locales aliados a estas luchas, que se han unido y resignificado el territorio, los derechos, y la ciudadanía por medio de la acción política universalista o cosmopolita.

La división entre trabajadores en el marco del aislamiento y la condición de deportabilidad generadas por las políticas de la multiplicación de las fronteras parecen estar siendo transformada. La solidaridad y el apoyo mutuo, la confianza y el reconocimiento de unos hacia otros parecen estar sustituyendo las jerarquías, la competencia, la división, y el temor de unos con respecto de los otros, que en mucho explica las incapacidades en el pasado de lograr un estatus permanente para las y los "sin papeles". Esto es, estas luchas parecen estar rescatando saberes, sensibilidades y prácticas políticas que fueron parcialmente subyugadas en el capitalismo avanzado, en el contexto canadiense.

El espacio o los espacios territoriales de los cuales ha sido vetada la presencia de los indocumentados, y en los cuales habitan con permanente temor a ser atrapados, encerrados, removidos y deportados, ahora en el contexto del covid, de forma paradójica, parecen también estar siendo transformados en su significado. En estos territorios, donde un indocumentado tradicionalmente vive en aislamiento y en soledad, se están creando nuevas relaciones de solidaridad inter-racial e inter-étnica y de clase, así como creando nuevos símbolos y nuevas prácticas de inclusión radical. Nuevas ilusiones, y nuevas formas de acción social y simbólica por medio de la participación política están apareciendo, todo lo cual parece estar neutralizando los efectos dañinos de la deportabilidad, abriendo grietas en los muros de las fronteras de la exclusión y elaborando una política que respeta, protege y defiende la vida.

\section{Conclusión}

Como se ha discutido en este trabajo, los procesos de multiplicación de las fronteras que se produjo en cierta medida por la multiplicidad de figuras de trabajo, particularmente trabajo migrante en los países centrales del sistema mundo, tuvo como una de sus consecuencias la multiplicación de las jerarquizaciones, las diferencias y la separación entre los trabajadores migrantes de estatus precarios. En los tiempos de covid, sin embargo, ocurrió un fenómeno paradójico. Por un lado, lo que se denomina la multiplicación de las fronteras tendió a acentuarse. Las po- 
líticas públicas de protección a la población con respecto del covid, que excluyó a las y los indocumentados, generó lo que se ha llamado aquí la hípermultiplicación de las fronteras. Los toques de queda, las cuarentenas obligatorias, la pérdida de trabajo e ingresos, la inseguridad alimentaria, el temor de asistir a los hospitales, el aislamiento, todo eso en el marco de la exclusión de la política de apoyo institucional, incentivó la precariedad entre las poblaciones de migrantes de estatus precarios en Canadá.

Sin embargo, esta situación de precariedad y exclusión radical, y el trabajo político de las organizaciones pro-migrantes logró movilizar a las poblaciones de una manera formidable. En este proceso de respuestas, que incluyeron algunas basadas en el apoyo mutuo, la solidaridad, la redistribución y el reconocimiento, se han generado prácticas sociales y formas de sociabilidad política que incluyen el rescate de saberes sociales y políticos que habían sido subyugadas en el capitalismo avanzado; a saber, la práctica del apoyo mutuo, el amor radical, la solidaridad interétnica e interracial, y el cuidado y protección de la vida.

La centralidad de la vida como objeto de la política, la creación de territorios cosmopolitas e incluyentes, el rescate de prácticas subyugadas en el discurso político hegemónico, como el apoyo mutuo y la solidaridad, no solo están contestando y transformando el significado que tiene la noción de frontera para los indocumentados y otros migrantes de estatus precario, sino que también parecen tener la potencialidad de inaugurar un nuevo horizonte de la práctica política; donde las fronteras territoriales y simbólicas son regidas no por la separación y la exclusión, sino por la unión y la alianza entre las multitudes y la multiplicidad de los gestos de amor, solidaridad y de reconocimiento profundo entre los seres humanos. 


\section{Bibliografía}

Arrighi, G. (2009). The Long Twentieth Century. Money, Power and the Origins of Our Times. New York, NY: Verso Books.

Balibar, E. (2002). What is a border? In: Politics and the Other Scene. New York, NY: Verso, pp: 75-86.

Basok, T., Belanger, D. y Rivas, E. (2014). 'Reproducing Deportability: Migrant Agricultural Workers in South-western Ontario.' Journal of Ethnic and Migration Studies, 40 (9): 1394-1413.

Basok, T. (2002). Tortillas and Tomatoes: Transmigrant Mexican Harvesters in Canada. Montreal, PQ: McGill-Queen's University Press

Basok, T. (1999). 'Free to Be Unfree: Mexican Guest Workers in Canada.' Labour, Capital and Society, 32(2): 192-221.

Bourdieu, P. ([1972] 2012). Outline of a theory of practice. Cambridge, UK: Cambridge University Press.

Canadian Council for Refugees. (2020). COVID-19 Q\&A. Questions relating to refugee claims. Website: https://ccrweb.ca/en/covid-19-qa

De Genova, N. (2002). Migrant «lllegality» and Deportability in Everyday Life. Annual Review of Anthropology, 31, 419-447

Durand, J. (2015). 'De programas bilaterales y visas unilaterales. Seis tesis sobre el trabajo migrante temporal.'En: Sara Lara Flores, Jorge Pantaleón y Sánchez Gómez Martha (Eds.) Hacia el Otro Norte: Mexicanos en Canadá (pp: 75-88). Buenos Aires: CLACSO.

Dussel, E. (2006). 20 Tesis de Política. Distrito Federal, MX: CREFAL-Siglo XXI.

Deleuze, G. y Guattari, F. (2009 [1972]). Anti-Oedipus. Capitalism and Schizophrenia. New York, NY: Penguin Classics.

Faraday, F. (Febrero 24, 2021)."COVID-19's impact on migrant workers adds urgency to calls for permanent status". The Conversation. Website: https://theconversation.com/ covid-19s-impact-on-migrant-workers-adds-urgency-to-calls-for-permanentstatus-148237

Foucault, M. (2003 [1997]). Society must be defended. London, UK: Penguin Classics.

Foucault, M. (2009). Security, Territory, Population:Lectures at the Collège de France 1977-1978. New York, NY: Palgrave Macmillan.

Ganz, M. (2009). Why David Sometimes Wins. Leadership, Organization, and Strategy in the California Farm Worker Movement. New York, NY: Oxford University Press.

Goldring, L. y Landolt, P. (2013).'The Social Production of Non-Citizenship: The Consequences of Intersecting Trajectories of Precarious Legal Status and Precarious Work.'In: 
L.Goldring \& P. Landolt (eds.) Producing and Negotiating Non-Citizenship: Precarious Legal Status in Canada (Pp: 154-174). Toronto, ON: University of Toronto Press.

Hardt, M. y Negri, A. (2004). Multitude: War and Democracy in the Age of Empire. New York, NY: The Penguin Press.

Harvey, D. (1989). The Condition of Postmodernity: An Enquiry into the Origins of Cultural Change. New York, NY: Blackwell Publishing.

Harvey, D. (2001). Spaces of capital: Towards a critical geography. Edinburgh, SC: Edinburgh University Press.

Harvey, D. (2003). The New Imperialism. New York, NY: Oxford University Press.

Harvey, D. (2010). The Enigma of Capital and the Crisis of Capitalism. New York, NY: Oxford University Press.

Harvey, D. (2005). A Brief History of Neoliberalism. Oxford, NY: Oxford University Press.

Marx, K. (1977 [1939]). Grundrisse. Foundations of the Critique of Political Economy. New York, NY: Penguin Books.

Mbembe, A. (2019). Necropolitics. Duke University Press Books. Pp: 66-92.

Mezzadra, S. y Neilson, B. (2013). Border as Method, or, the Multiplication of Labor. Duke University Press Books.

Mezzadra, S. (2015). The proliferation of borders and the right to escape. In Y. Jansen, R. Celikates, \& J. de Bloois (Eds.), The Irregularization of Migration in Contemporary Europe: Detention, Deportation, Drowning (pp:121-135). London, UK: Rowman \& Littlefield International.

Mezzadra, S. (Diciembre 1, 2018). "La frontera como método. Apuntes de Uso y Combate: Conversacipon con Sandro Mezzadra." Madrid, ES:Traficantes de Sueños. Vínculo a entrevista:https://traficantes.net/actividad/una-conversaci\%C3\%B3n-con-sandromezzadra-en-madrid-la-frontera-como-m\%C3\%A9todo

Porter, J. (1970). The Vertical Mosaic: An Analysis of Social Class and Power in Canada. Toronto, ON: University of Toronto Press.

Preibisch, K. (2007). 'Local Produce, Foreign Labor: Labor Mobility Programs and Global Trade Competitiveness in Canada.' Rural Sociology, 72(3): 418-449.

Priebisch, K. (2015). 'Los trabajadores migrantes y los cambios en los regímens laborales en la produccion agrícola contemporánea de Canadá.' En: Sara Lara Flores, Jorge Pantaleón y Martha Sánchez Gómez (Eds.) Hacia el Otro Norte: Mexicanos en Canadá (pp: 115-137). Buenos Aires: CLACSO.

Sassen, S. (1988). The Mobility of Labor and Capital. A Study in International Investment and Labor Flow. Cambridge, MA: Cambridge University Press.

Sheldon, M. (2020). "We need all hands on deck': Canadian farmers struggle with labour shortfall due to COVID-19." CBC News Canada. 
Verduzco, G. (2015). “EI PTAT y los programas de trabajadores temporales. Una visión crítica” En: Sara Lara Flores, Jorge Pantaleón y Sánchez Gómez Martha (Eds.) Hacia el Otro Norte: Mexicanos en Canadá (Pp: 89-114). Buenos Aires, ARG: CLACSO.

Wallerstein, I. (2005). La crisis estructural del capitalismo. San Cristóbal de las Casas, MX: CIDECI-Universidad de la Tierra.

Wallerstein, I. (2010 [1974]). The Modem World System, Capitalist Agriculture and the Origins of the European World Economy in the Sixteenth Century. Berkeley and Los Angeles, CAL: University of California Press.

Wallerstein, I. (2011). "Borders, Borders Everywhere, and Not a Drop to Drink." Provost's Lecture, Stony Brook University, Long Island, New York. Acceso a la conferencia: www.youtube.com/watch?v=5UUjYzrjHn4\&list=PL913938DD774F23D9\&index $=87$ Wallerstein, Immanuel provost lectures.

Wallerstein, I. (2004). World-Systems Analysis. An Introduction. Durham, NC: Duke University Press.

Wallerstein, I. (2016). 'Free Flows and real Obstacles. Who wants laissez faire?' In: Jones, Terry-Ann \& Eric Mielants (eds.) Mass Migration in the World System. Past, Present and Future (pp: 13-21). New York, NY: Routledge.

Walsh, J. (2012). "Mass Migration and the Mass Society: Fordism, Immigration Policy and the Post-war Long Boom in Canada and Australia, 1947-1970." Journal of Historical Sociology, 25(3). 